\section{Case Reports in Ophthalmology}

\title{
Equatorial Staphyloma Associated with Neurofibromatosis Type 1
}

\author{
Yoshiaki Shimada Masayuki Horiguchi \\ Department of Ophthalmology, Fujita Health University Hospital, Toyoake, Japan
}

\section{Keywords}

Myopia $\cdot$ Neurofibromatosis type $1 \cdot$ Staphyloma

\begin{abstract}
We report a case of a 38-year-old man who presented with a recently self-detected lump under his left eyebrow. Previous ophthalmological history was unremarkable except for unilateral high myopia (left eye) since childhood. The appearance of the left eye was seemingly normal; however, with the top lid pulled up on downward gaze, a dark brown bulge emerged. The bulge was $10 \times 7 \mathrm{~mm}$ and approximately $4 \mathrm{~mm}$ in height, and was covered by the extended superior rectus muscle. The diagnosis of equatorial staphyloma was made after coronal T1-weighted magnetic resonance imaging of the orbit revealed the dilatation of the vitreous cavity. Ocular movements were fully maintained and visual acuity was largely spared: $20 / 15$ in the right eye without correction and 20/25 in the left eye with -10.00 spheres and $-4.00 \times 80$ degrees cylinders. His past and family histories were unremarkable; however, small neurofibromas and café au lait spots all over his body led to the diagnosis of neurofibromatosis type 1 (NF1). From this case, similar to previous reports, we suggest that manifestations of NF1 are extremely variable and unpredictable.




\section{Case Reports in Ophthalmology}

\section{Introduction}

Neurofibromatosis type 1 (NF1, also known as von Recklinghausen disease) is one of the most common autosomal-dominant genetic disorders with many associated ocular findings/disorders, most typically Lisch nodules, retinal/choroidal hamartomas, congenital glaucoma, and optic pathway gliomas [1-3]. NF1 may also be associated with other various ocular abnormalities [1-3] including, rarely, retinal ischemia [4] or anterior scleral staphyloma [5]. We diagnosed a patient with NF1 after he presented with an equatorial staphyloma. The staphyloma had been missed during repeated previous examinations by ophthalmologists and was eventually found by the patient himself.

\section{Case Report}

A 38-year-old man noticed a lump under his left eyebrow after palpation with his finger. He had been diagnosed with unilateral high myopia (left eye) as a child, and was seen yearly by an ophthalmologist. He had no difficultly with vision in the right eye, and therefore did not wear refractive correction. However, this time, investigation of the lump led an ophthalmologist to identify a principal lesion in his left eye. The appearance of the left eye was seemingly quite normal (fig. 1a); however, when the top lid was pulled up on downward gaze, a dark brown bulge emerged (fig. 1b).

The bulge was $10 \mathrm{~mm}$ circumferentially, $7 \mathrm{~mm}$ radially, and approximately $4 \mathrm{~mm}$ in height, and covered by the extended superior rectus muscle (fig. 2a). The proximal end corresponded to the insertion of the superior rectus muscle, approximately $8 \mathrm{~mm}$ away from the limbus; the distance had probably previously hindered detection of the lesion at examinations. The brown appearance was due to the uvea seen through the thinned sclera. The pupil in the left eye was shifted upward, and the iris ectropion was observed on the upper pupillary border (fig. 2b). Iris pattern was absent and multiple subtle protuberances were scattered on the pupillary border without apparent nodules. The diagnosis of equatorial staphyloma was made based on coronal T1-weighted magnetic resonance imaging of the orbit showing dilatation of the vitreous cavity (fig. 2c, white arrow).

In spite of the deformity, ocular movements were fully maintained. The right eye was normal. Visual acuity was 20/15 in the right eye without correction and 20/25 in the left eye with -10.00 spheres and $-4.00 \times 80$ degrees cylinders, and the intraocular pressure was 15 $\mathrm{mm} \mathrm{Hg}$ in both eyes.

His past and family medical histories were unremarkable; his only ailment was myopia in the left eye, and none of his relatives had a known inheritable disease. However, small neurofibromas and café au lait spots all over his body led to the diagnosis of NF1.

\section{Discussion}

Anterior scleral staphyloma associated with NF1 was reported by Kremer and Gaton in 1991 [5]. The staphyloma was adjacent to the cornea, and easily to be found on a 28-year-old woman with neurofibromas, café au lait spots, scoliosis, and intellectual disability. They did not find a precedent report of staphyloma in NF1 and, thus, mentioned that the association between staphyloma and NF1 might be a coincidence. However, they also speculated that the staphyloma might share a similar pathogenetic mechanism as the absence of the greater 
wing of the sphenoid or orbital roof reported in NF1 [5], as regional scleral dysplasia is associated with staphyloma.

NF1 is caused by a defect in the NF1 gene located on the long arm of chromosome 17 at position $17 \mathrm{q} 11.2$, that encodes a 2,818-amino acid protein, neurofibromin 1 [1-3]. Neurofibromin 1 is a complicated protein with multiple functions involved in the regulation of cellular proliferation [3]. It works as a tumor suppressor; thus, its absence leads to abnormal cellular proliferation [1-3]. Besides causing various tumors, NF1 may indicate organ dysplasia [1, 3], although the pathogenesis is not fully explained. Chen et al. [6] reported a case of anophthalmia (absent of the whole globe from the orbit) in a 27-year-old woman with NF1. Similar to Kremer and Gaton [5], they also hypothesized that anophthalmia may have been a coincidence finding. In addition, we admit the possibility of coincidence; however, we still postulate that both staphyloma and anophthalmia could be caused by eyeball dysplasia, a rate phenotype of NF1. Either way, the previous reports [5, 6] and unusual staphyloma in this case epitomized the manifestations associated with NF1, which are extremely variable and unpredictable [1-6].

\section{Statement of Ethics}

The authors have no ethical conflicts to disclose.

\section{Disclosure Statement}

The authors report no conflicts of interest. This is an unfunded study.

\section{References}

1 Sippel KC: Ocular findings in neurofibromatosis type 1. Int Ophthalmol Clin 2001;41:25-40.

2 Kerrison JB: Phacomatoses; in Miller NR, Newman NJ, MD, Biousse V, Kerrison JB (eds): Walsh \& Hoyt's Clinical Neuro-Ophthalmology, ed 6. Philadelphia, Lippincott Williams \& Wilkins, 2005, vol 2, pp 18231891.

3 Savar A, Cestari DM: Neurofibromatosis type I: genetics and clinical manifestations. Semin Ophthalmol 2008;23:45-51.

4 Pichi F, Morara M, Lembo A, Ciardella AP, Meduri A, Nucci P: Neovascular glaucoma induced by peripheral retinal ischemia in neurofibromatosis type 1: management and imaging features. Case Rep Ophthalmol 2013;4:69-73.

-5 Kremer I, Gaton DD: Anterior scleral staphyloma associated with neurofibromatosis. Ann Ophthalmol 1991;23:356-358.

6 Chen S, Pu JL, Zhang JM, Hong Y: Anophthalmia: an uncommon manifestation of neurofibromatosis type 1. J Craniofac Surg 2011;22:e47-e48. 


\begin{tabular}{|c|c|}
\hline \multirow{2}{*}{\multicolumn{2}{|c|}{ Case Rep Ophthalmol 2016;7:384-388 }} \\
\hline & \\
\hline $10.1159 / 000448211$ & $\begin{array}{l}\text { ( } 2016 \text { The Author(s). Published by S. Karger AG, Basel } \\
\text { www.karger.com/cop }\end{array}$ \\
\hline
\end{tabular}

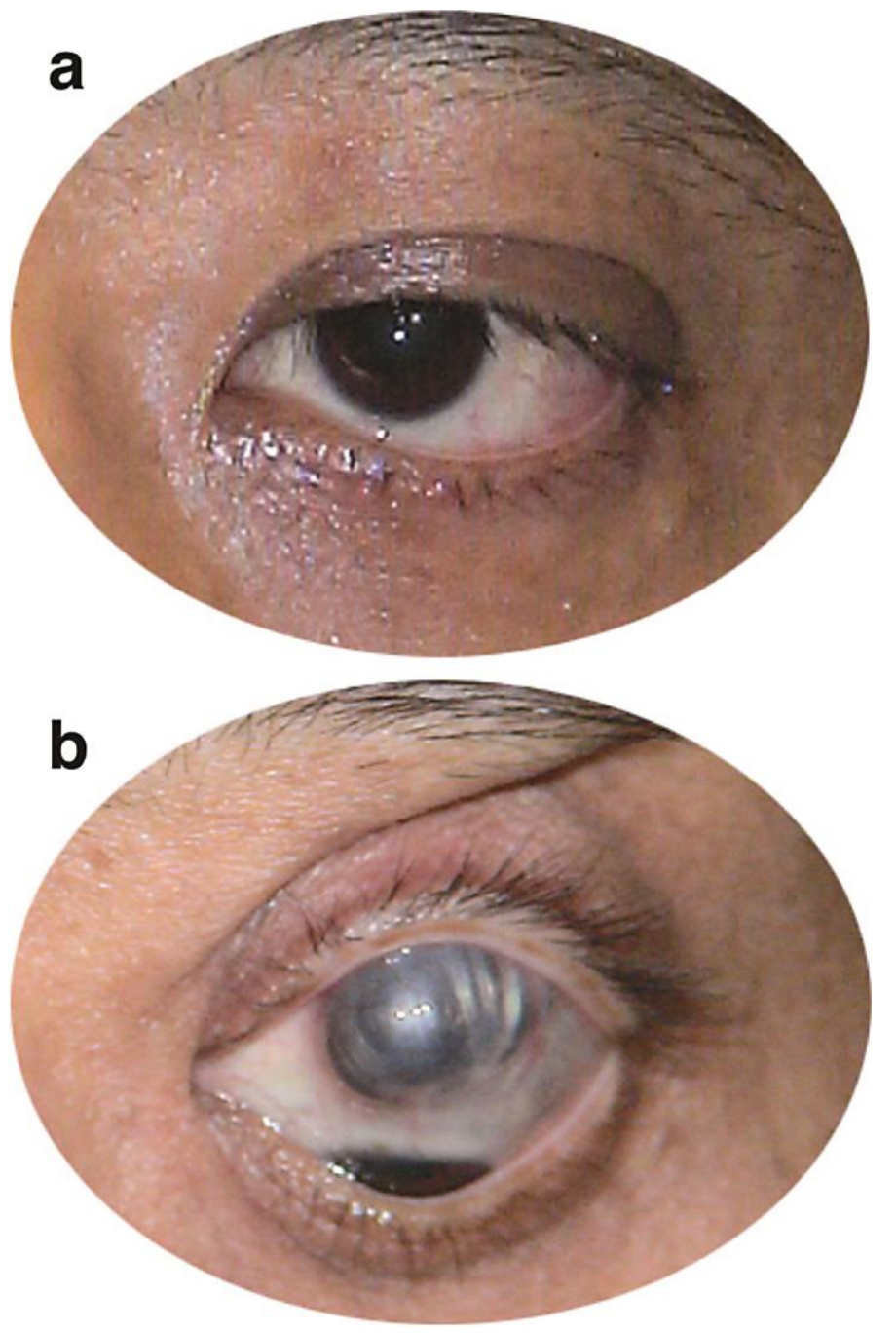

Fig. 1. Appearance of the left eye of a 38-year-old man. While its exterior ordinarily looked normal (a), a dark brown bulge emerged when the upper eyelid was uplifted on inferior gaze (b). 


\section{Case Reports in Ophthalmology}
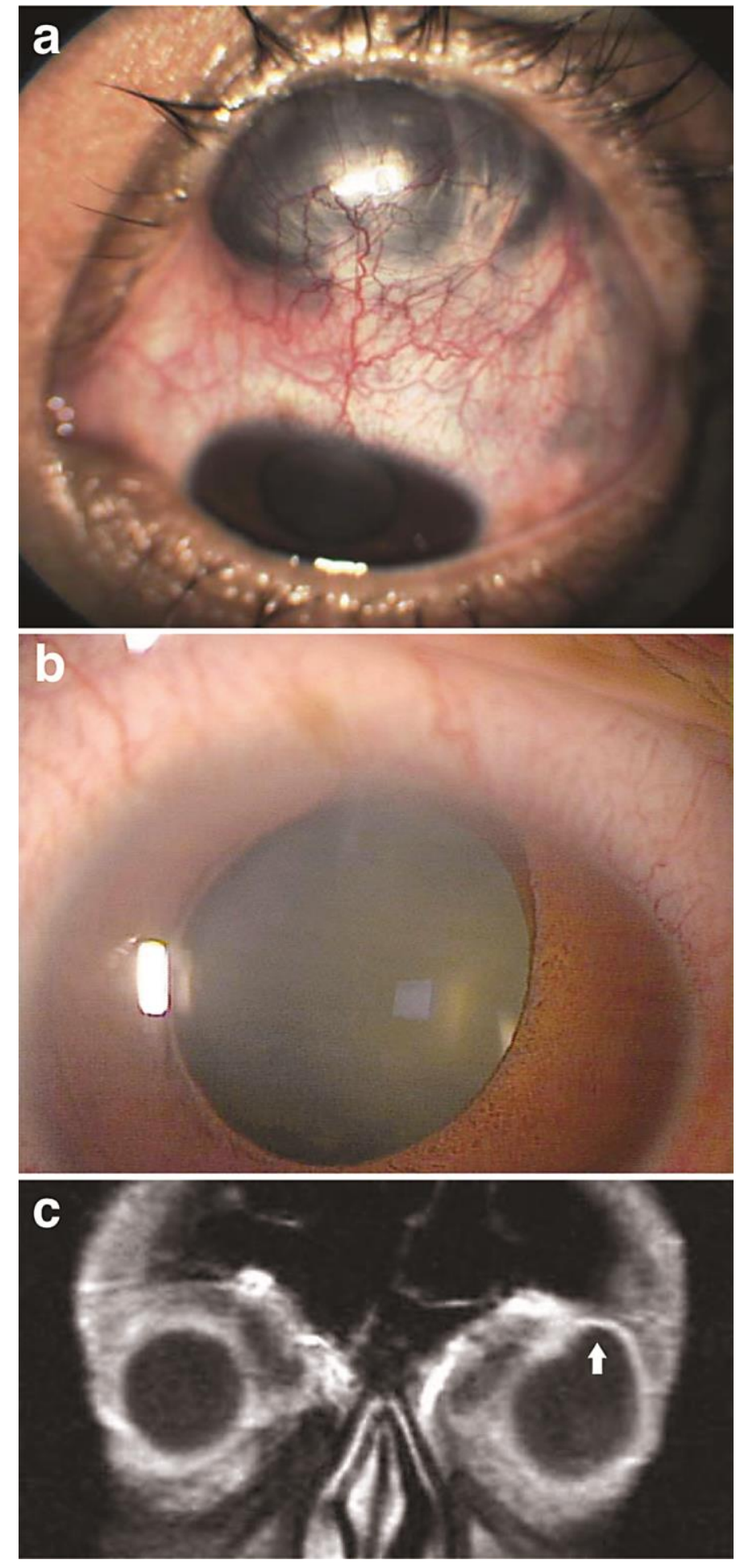

Fig. 2. Images of the left eye in a 38-year-old man. A protrusion with a width of $10 \mathrm{~mm}$, a length of $7 \mathrm{~mm}$ and a height of approximately $4 \mathrm{~mm}$ was detected (a). Pupil shifted upward with the iris ectropion on the upper pupillary border (b). Coronal magnetic resonance image showed the protrusion was a dilatation of the vitreous cavity, suggesting staphyloma (c, white arrow). 